\title{
How to get started in quality improvement
}

\section{OPEN ACCESS}

\author{
Bryan Jones improvement fellow ${ }^{1}$, Emma Vaux consultant nephrologist ${ }^{2}$, Anna Olsson-Brown \\ research fellow ${ }^{3}$
}

${ }^{1}$ The Health Foundation, London, UK; ${ }^{2}$ Royal Berkshire NHS Foundation Trust. Reading, UK; ${ }^{3}$ Department of Molecular and Clinical Pharmacology, The Institute of Translational Medicine, University of Liverpool, Liverpool, UK

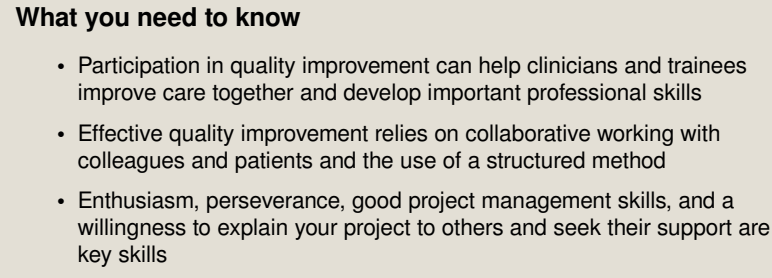

- Participation in quality improvement can help clinicians and trainees improve care together and develop important professional skills

- Effective quality improvement relies on collaborative working with colleagues and patients and the use of a structured method

- Enthusiasm, perseverance, good project management skills, and a willingness to explain your project to others and seek their support are key skills

Quality improvement (box 1) is a core component of many undergraduate and postgraduate curriculums..$^{1-5}$ Numerous healthcare organisations, ${ }^{6}$ professional regulators, ${ }^{7}$ and policy makers ${ }^{8}$ recognise the benefits of training clinicians in quality improvement.

\section{Box 1: Defining quality improvement ${ }^{1}$ \\ Quality improvement aims to make a difference to patients by improving safety, effectiveness, and experience of care by: \\ Using understanding of our complex healthcare environment Applying a systematic approach \\ Designing, testing, and implementing changes using real time measurement for improvement}

Engaging in quality improvement enables clinicians to acquire, assimilate, and apply important professional capabilities ${ }^{7}$ such as managing complexity and training in human factors. ${ }^{1}$ For clinical trainees, it is a chance to improve care'; develop leadership, presentation, and time management skills to help their career development ${ }^{10}$; and build relationships with colleagues in organisations that they have recently joined. ${ }^{11}$ For more experienced clinicians, it is an opportunity to address longstanding concerns about the way in which care processes and systems are delivered, and to strengthen their leadership for improvement skills. ${ }^{12}$
The benefits to patients, clinicians, and healthcare providers of engaging in quality improvement are considerable, but there are many challenges involved in designing, delivering, and sustaining an improvement intervention. These range from persuading colleagues that there is a problem that needs to be tackled, through to keeping them engaged once the intervention is up and running as other clinical priorities compete for their attention. ${ }^{13}$ You are also likely to have competing priorities and will need support to make time for quality improvement. The organisational culture, such as the extent to which clinicians are able to question existing practice and try new ideas, ${ }^{14-16}$ also has an important bearing on the success of the intervention.

This article describes the skills, knowledge, and support needed to get started in quality improvement and deliver effective interventions.

\section{What skills do you need?}

Enthusiasm, optimism, curiosity, and perseverance are critical in getting started and then in helping you to deal with the challenges you will inevitably face on your improvement journey.

Relational skills are also vital. At its best quality improvement is a team activity. The ability to collaborate with different people, including patients, is vital for a project to be successful. ${ }^{17}{ }^{18}$ You need to be willing to reach out to groups of people that you may not have worked with before, and to value their ideas. ${ }^{19}$ No one person has the skills or knowledge to come up with the solution to a problem on their own.

Learning how systems work and how to manage complexity is another core skill. ${ }^{20}$ An ability to translate quality improvement approaches and methods into practice (box 2), coupled with good project and time management skills, will help you design and implement a robust project plan. ${ }^{27}$ 


\section{Box 2: Quality improvement approaches}

Healthcare organisations use a range of improvement methods, ${ }^{2122}$ such as the Model for Improvement, where changes are tested in small cycles that involve planning, doing, studying, and acting (PDSA), ${ }^{23}$ and Lean, which focuses on continually improving processes by removing waste, duplication, and non-value adding steps. ${ }^{24}$ To be effective, such methods need to be applied consistently and rigorously, with due regard to the context. ${ }^{25}$ In using PDSA cycles, for example, it is vital that teams build in sufficient time for planning and reflection, and do not focus primarily on the "doing." 26

Equally important is an understanding of the measurement for improvement model, which involves the gradual refinement of your intervention based on repeated tests of change. The aim is to discover how to make your intervention work in your setting, rather than to prove it works, so useful data, not perfect data, are needed. ${ }^{28}{ }^{29}$ Some experience of data collection and analysis methods (including statistical analysis tools such as run charts and statistical process control) is useful, but these will develop with increasing experience. ${ }^{3031}$

Most importantly, you need to enjoy the experience. It is rare that a clinician can institute real, tangible change, but with quality improvement this is a real possibility, which is both empowering and satisfying. Finally, don't worry about what you don't know. You will learn by doing. Many skills needed to implement successful quality improvement will be developed as you go; this is a fundamental feature of quality improvement.

\section{How do you get started?}

The first step is to recruit your improvement team. Start with colleagues and patients, ${ }^{32}$ but also try to bring in people from other professions, including non-clinical staff. You need a blend of skills and perspectives in your team. Find a colleague experienced in quality improvement who is willing to mentor or supervise you.

Next, identify a problem collaboratively with your team. Use data to help with this (eg, clinical audits, registries of data on patients' experiences and outcomes, and learning from incidents and complaints) (box 3). Take time to understand what might be causing the problem. There are different techniques to help you (process mapping, five whys, appreciative inquiry). ${ }^{35-37}$ Think about the contextual factors that are contributing to the problem (eg, the structure, culture, politics, capabilities and resources of your organisation).

\section{Box 3: Clinical audit and quality improvement}

Quality improvement is an umbrella term under which many approaches sit, clinical audit being one. ${ }^{33}$ Clinical audit is commonly used by trainees to assess clinical effectiveness. Confusion of audit as both a term for assurance and improvement has perhaps limited its potential, with many audits ending at the data collection stage and failing to lead to improvement interventions. Learning from big datasets such as the National Clinical Audits in the UK is beginning to shift the focus to a quality improvement approach that focuses on identifying and understanding unwanted variation in the local context; developing and testing possible solutions, and moving from one-off change to multiple cycles of change. ${ }^{34}$

Next, develop your aim using the SMART framework: Specific (S), Measurable (M), Achievable (A), Realistic (R), and Timely (T). ${ }^{38}$ This allows you to assess the scale of the intervention and to pare it down if your original idea is too ambitious. Aligning your improvement aim with the priorities of the organisation where you work will help you to get management and executive support. $^{39}$

Having done this, map those stakeholders who might be affected by your intervention and work out which ones you need to approach, and how to sell it to them. ${ }^{40}$ Take the time to talk to them. It will be appreciated and increases the likelihood of buy in, without which your quality improvement project is likely to fail irrespective of how good your idea is. You need to be clear in your own mind about the reasons you think it is important. Developing an "elevator pitch" based on your aims is a useful technique to persuade others, ${ }^{38}$ remembering different people are hooked in for different reasons.

The intervention will not be perfect first time. Expect a series of iterative changes in response to false starts and obstacles. Measuring the impact of your intervention will enable you to refine it. ${ }^{28}$ Time invested in all these aspects will improve your chances of success.

Right from the start, think about how improvement will be embedded. Attention to sustainability will mean that when you move to your next job your improvement efforts, and those of others, and the impact you have collectively achieved will not be lost. ${ }^{4142}$

\section{What support is needed?}

You need support from both your organisation and experienced colleagues to translate your skills into practice. Here are some steps you can take to help you make the most of your skills:

- Find the mentor or supervisor who will help identify and support opportunities for you. Signposting and introduction to those in an organisation who will help influence (and may hinder) your quality improvement project is invaluable

- Use planning and reporting tools to help manage your project, such as those in NHS Improvement's project management framework ${ }^{27}$

- Identify if your local quality improvement or clinical audit team may be a source of support and useful development resource for you rather than just a place to register a project. Most want to support you.

- Determine how you might access (or develop your own) local peer to peer support networks, coaching, and wider improvement networks (eg, NHS networks; Q network ${ }^{434}$ )

- Use quality improvement e-learning platforms such as those provided by Health Education England or NHS Education for Scotland to build your knowledge $\mathrm{e}^{45} 46$

- Learn through feedback and assessment of your project (eg, via the QIPAT tool ${ }^{47}$ or a multi-source feedback tool. $^{4849}$

Quality improvement approaches are still relatively new in the education of healthcare professionals. Quality improvement can give clinicians a more productive, empowering, and educational experience. Quality improvement projects allow clinicians, working within a team, to identify an issue and implement interventions that can result in true improvements in quality. Projects can be undertaken in fields that interest clinicians and give them transferable skills in communication, leadership, project management, team working, and clinical governance. Done well, quality improvement is a highly beneficial, positive process which enables clinicians to deliver true change for the benefit of themselves, their organisations, and their patients. 
Quality improvement in action: three doctors and a medical student talk about the challenges and practicalities of quality improvement

This box contains four interviews by Laura Nunez-Mulder with people who have experience in quality improvement.

\section{Alex Thompson, medical student at the University of Cambridge,} is in the early stages of his first quality improvement project

We are aiming to improve identification and early diagnosis of aortic dissections in our hospital. Our supervising consultant suspects that the threshold for organising computed tomography angiography for a suspected aortic dissection is too high, so to start with, my student colleague and I are finding out what proportion of CT angiograms result in a diagnosis of aortic dissection.

I fit the project around my studies by working on it in small chunks here and there. You have to be very self motivated to see a project through to the end.

Anna Olsson-Brown, research fellow at the University of Liverpool, engaged in quality improvement in her F1 year, and has since supported junior doctors to do the same. This extract is adapted from her BMJ Opinion piece (https://blogs.bmj.com/ bmj/)

Working in the emergency department after my F1 job in oncology, I noticed that the guidelines on neutropenic sepsis antibiotics were relatively unknown and even less frequently implemented. A colleague and I devised a neutropenic sepsis pathway for oncology patients in the emergency department including an alert label for blood tests. The pathway ran for six months and there was some initial improvement, but the benefit was not sustained after we left the department.

As an ST3, I mentored a junior doctor whose quality improvement project led to the introduction of a syringe driver prescription sticker that continues to be used to this day.

My top tips for those supporting trainees in quality improvement:

- Make sure the project is sufficiently narrow to enable timely delivery

- Ensure regular evaluation to assess impact

- Support trainees to implement sustainable pathways that do not require their ongoing input.

Amar Puttanna, consultant in diabetes and endocrinology at Good Hope Hospital, describes a project he carried out as a chief registrar of the Royal College of Physicians

The project of which I am proudest is a referral service we launched to review medication for patients with diabetes and dementia. We worked with practitioners on the older adult care ward, the acute medical unit, the frailty service, and the IT teams, and we promoted the project in newsletters at the trust and the Royal College of Physicians.

The success of the project depended on continuous promotion to raise awareness of the service because junior doctors move on frequently. Activity in our project reduced after I left the trust, though it is still ongoing and won a Quality in Care Award in November 2018.

Though this project was a success, not everything works. But even the projects that fail contain valuable lessons.

Mark Taubert, consultant in palliative medicine and honorary senior lecturer for Cardiff University School of Medicine, launched the TalkCPR project

Speaking to people with expertise in quality improvement helped me to narrow my focus to one question: "Can videos be used to inform both staff and patients/carers about cardiopulmonary resuscitation and its risks in palliative illness?" With my team I created and evaluated TalkCPR, an online resource that has gone on to win awards (talkcpr.wales).

The most challenging aspect was figuring out which tools might get the right information from any data I collected. I enrolled on a Silver Improving Quality Together course and joined the Welsh Bevan Commission, where I learned useful techniques such as multiple PDSA (plan, do, study, act) cycles, driver diagrams, and fishbone diagrams.

\section{Education into practice}

In designing your next quality improvement project:

What will you do to ensure that you understand the problem you are trying to solve?

- How will you involve your colleagues and patients in your project and gain the support of managers and senior staff?

- What steps will you take right from the start to ensure that any improvements made are sustained?
How patients were involved in the creation of this article

The authors have drawn on their experience both in partnering with patients in the design and delivery of multiple quality improvement activities and in participating in the Academy of Medical Royal Colleges Training for Better Outcomes Task and Finish Group in which patients were involved at every step. Patients were not directly involved in writing this article.

\section{Sources and selection material}

Evidence for this article was based on references drawn from authors' academic experience in this area, guidance from organisations involved in supporting quality improvement work in practice such as NHS Improvement, The Health Foundation, and the Institute for Healthcare Improvement, and authors' experience of working to support clinical trainees to undertake quality improvement.

Competing interests: The $B M J$ has judged that there are no disqualifying financial ties to commercial companies.

The authors declare the following other interests: none.

Further details of The BMJ policy on financial interests is here: https://www.bmj. com/about-bmj/resources-authors/forms-policies-and-checklists/declarationcompeting-interests

Contributors: BJ produced the initial outline after discussions with EV and AOB. AO-B produced a first complete draft, which EV reworked and expanded. BJ then edited and finalised the text, which was approved by EV and AO-B. The revisions in the resubmitted version were drafted by $B J$ and edited and approved by $E V$ and $\mathrm{AO}-\mathrm{B}$. $\mathrm{BJ}$ is responsible for the overall content as guarantor.

Provenance and peer review: This article is part of a series commissioned by The BMJ based on ideas generated by a joint editorial group with members from the Health Foundation and The BMJ, including a patient/carer. The BMJ retained full editorial control over external peer review, editing, and publication. Open access fees and The BMJ's quality improvement editor post are funded by the Health Foundation.

1 Academy of Medical Royal Colleges (AoMRC). Quality improvement: training for better outcomes. March 2016. http://www.aomrc.org.uk/reports-guidance/quality-improvementtraining-better-outcomes/

2 Vaux E, Went S, Norris M, Ingham J. Learning to make a difference: introducing quality improvement methods to core medical trainees. Clin Med (Lond) 2012;12:520-5. 10.7861/clinmedicine.12-6-520 23342404

3 Bethune R, Soo E, Woodhead P, Van Hamel C, Watson J. Engaging all doctors in continuous quality improvement: a structured, supported programme for first-year doctors across a training deanery in England. BMJ Qual Saf 2013;22:613-7.

10.1136/bmjqs-2013-001926 23661281

4 Teigland CL, Blasiak RC, Wilson LA, Hines RE, Meyerhoff KL, Viera AJ. Patient safety and quality improvement education: a cross-sectional study of medical students' preferences and attitudes. BMC Med Educ 2013;13:16. 10.1186/1472-6920-13-16 23379673

5 Nair P, Barai I, Prasad S, Gadhvi K. Quality improvement teaching at medical school: a student perspective. Adv Med Educ Pract 2016;7:171-2. 10.2147/AMEP.S101395 27051330

6 Jones B, Woodhead T. Building the foundations for improvement-how five UK trusts built quality improvement capability at scale within their organisations. The Health Foundation. February 2015. https://www.health.org.uk/publication/building-foundationsimprovement

7 General Medical Council (GMC). Generic professional capabilities framework. May 2017. https://www.gmc-uk.org/-/media/documents/generic-professional-capabilities-framework0817_pdf-70417127.pdf

8 NHS improvement (NHSI). Developing people-improving care A national framework for action on improvement and leadership development in NHS-funded services. December 2016. https://improvement.nhs.uk/resources/developing-people-improving-care/

9 The Health Foundation. Involving junior doctors in quality improvement: evidence scan September 2011. https://www.health.org.uk/publication/involving-junior-doctors-qualityimprovement

10 Zarkali A, Acquaah F, Donaghy G, et al. Trainees leading quality improvement. A trainee doctor's perspective on incorporating quality improvement in postgraduate medical training. Faculty of Medical Leadership and Management. March 2016. https://www.fmlm.ac.uk sites/default/files/content/resources/attachments/FMLM\%20TSG\%20Think\%20Tank\% 20Trainees\%20leading\%20quality\%20improvement.pdf

11 Hillman T, Roueche A. Quality improvement. BMJ 2011;342. 10.1136/bmj.d2060.

12 Bohmer R. The instrumental value of medical leadership: Engaging doctors in improving services. The King's Fund. 2012. https://www.kingsfund.org.uk/sites/default/files/ instrumental-value-medical-leadership-richard-bohmer-leadership-review2012-paper.pdf

13 Dixon-Woods M, McNicol S, Martin G. Ten challenges in improving quality in healthcare: lessons from the Health Foundation's programme evaluations and relevant literature. $B M J$ Qual Saf 2012;1e9. 10.1136/bmjqs-2011-000760

14 Curry LA, Brault MA, Linnander EL, etal . Influencing organisational culture to improve hospital performance in care of patients with acute myocardial infarction: a mixed-methods intervention study. BMJ Qual Saf 2018:27:207-17. 10.1136/bmjqs-2017-006989.https:// 
www.ncbi.nlm.nih.gov/entrez/query.fcgi? $\mathrm{cmd}=$ Retrieve\&db=PubMed\&list_uids=29101292\& dopt=Abstract 29101292

15 Carroll JS, Edmondson AC. Leading organisational learning in health care. Qual Saf Health Care 2002;11:51-6. 10.1136/qhc.11.1.51.https://www.ncbi.nlm.nih.gov/entrez/ query.fcgi?cmd=Retrieve\&db=PubMed\&list_uids=12078370\&dopt=Abstract 12078370

16 Mannion R, Davies $\mathrm{H}$. Understanding organisational culture for healthcare quality improvement. BMJ 2018;363:k4907. 10.1136/bmj.k4907 30487286

17 Richter A, Dawson J, West M. The effectiveness of teams in organisations: a meta-analysis. Int J Hum Resour Manage 2011;22:2749-6910.1080/09585192.2011.573971.

18 McPherson K, Headrick L, Moss F. Working and learning together: good quality care depends on it, but how can we achieve it?Qual Health Care 2001;10(Suppl 2):ii46-53.11700379

19 Lucas B, Nacer $\mathrm{H}$. The habits of an improver. Thinking about learning for improvement in health care. The Health Foundation. October 2015. https://www.health.org.uk/sites/ health/files/TheHabitsOfAnlmprover.pdf

20 Plsek PE, Greenhalgh T. Complexity science: The challenge of complexity in health care. BMJ 2001;323:625-8. 10.1136/bmj.323.7313.625 11557716

21 The Health Foundation. Quality Improvement made simple: what everyone should know about quality improvement. The Health Foundation. 2013. https://www.health.org.uk publication/quality-improvement-made-simple

22 Boaden R, Harvey G, Moxham C, Proudlove N. Quality improvement: theory and practice in healthcare. NHS Institute for Innovation and Improvement. 2008. https://www.england. nhs.uk/improvement-hub/publication/quality-improvement-theory-practice-in-healthcare/

23 Institute for Healthcare Improvement (IHI). IHI resources: How to improve. IHI. $2018 \mathrm{http}$ : //www.ihi.org/resources/Pages/Howtolmprove/default.aspx

24 Lean Enterprise Institute. What is lean? Lean Enterprise Institute. 2018. https://www.lean org/WhatsLean/

25 Bate P, Robert G, Fulop N, Øvretveit J, Dixon-Woods M. Perspectives on context. A selection of essays considering the role of context in successful quality improvement. The Health Foundation. 2014. https://www.health.org.uk/sites/health/files/ PerspectivesOnContext_fullversion.pdf

26 Reed JE, Card AJ. The problem with Plan-Do-Study-Act cycles. BMJ Qual Saf 2016;25:147-52.https://www.ncbi.nlm.nih.gov/entrez/query.fcgi?cmd=Retrieve $\mathrm{db}=$ PubMed\&list_uids=26700542\&dopt=Abstract10.1136/bmjqs-2015-005076 26700542

27 Improvement NHS. (NHSI) Quality, Service Improvement and Redesign Tools. Project management an overview. September 2017. https://improvement.nhs.uk/resources/projectmanagement-overview/

28 Clarke J, Davidge M, James L. The how-to guide for measurement for improvement. NHS Institute for Innovation and Improvement 2009. https://www.england.nhs.uk/improvementhub/wp-content/uploads/sites/44/2017/11/How-to-Guide-for-Measurement-for-Improvement. pdf

29 Nelson EC, Splaine ME, Batalden PB, Plume SK. Building measurement and data collection into medical practice. Ann Intern Med 1998;128:460-6. 10.7326/0003-4819-128-6-199803150-000079499330

30 Improvement NHS. (NHSI) Quality, Service Improvement and Redesign Tools. Run charts. January 2018. https://improvement.nhs.uk/resources/run-charts/

31 Improvement NHS. (NHSI) Quality, Service Improvement and Redesign Tools. Statistical process control tool. May 2018. https://improvement.nhs.uk/resources/statistical-processcontrol-tool/

32 Robert G, Cornwell J, Locock L, Purushotham A, Sturmey G, Gager M. Patients and staff as codesigners of healthcare services. BMJ 2015:350:g7714.10.1136/bmj.g7714 25670179
33 Burgess R, Moorhead J. New principles of best practice in clinical audit. 2 nd ed. Radcliffe publishing, 2011.

34 Royal College of Physicians. Unlocking the potential. Supporting doctors to use national clinical audit to drive improvement. April 2018. https://www.rcplondon.ac.uk/projects/ outputs/unlocking-potential-supporting-doctors-use-national-clinical-audit-drive

35 Improvement NHS. (NHSI) Quality, Service Improvement and Redesign Tools: conventional process mapping. January 2018. https://improvement.nhs.uk/resources/process-mappingconventional-model/

36 Institute for Healthcare Improvement (IHI) 5 Whys: Finding the root cause. IHI tool. 2018 http://www.ihi.org/resources/Pages/Tools/5-Whys-Finding-the-Root-Cause.aspx

37 Scottish Social Services Council (SSSC) Appreciative Inquiry Resource Pack. 2016. http: //learningzone.workforcesolutions.sssc.uk.com/course/view.php?id=67

38 Improvement NHS. (NHSI) Quality, Service Improvement and Redesign Tools: Developing your aims statement. January 2018. https://improvement.nhs.uk/resources/aims-statementdevelopment/

39 Pannick S, Sevdalis N, Athanasiou T. Beyond clinical engagement: a pragmatic model for quality improvement interventions, aligning clinical and managerial priorities. $B M J$ Qual Saf 2016;25:716-25. 10.1136/bmjqs-2015-004453 26647411

40 Improvement NHS. (NHSI) Quality, Service Improvement and Redesign Tools: Stakeholde Analysis. January 2018. https://improvement.nhs.uk/documents/2169/stakeholder-analysis. pdf

41 Royal College of Physicians. Unlocking the potential. Supporting doctors to use national clinical audit to drive improvement. April 2018. https://www.rcplondon.ac.uk/projects/ outputs/unlocking-potential-supporting-doctors-use-national-clinical-audit-drive

42 Maher L, Gustafson D, Evans A. Sustainability model and guide. NHS Institute for Innovation and Improvement. February 2010. http://webarchive.nationalarchives.gov.uk/ 20160805122935/http:/www.nhsiq.nhs.uk/media/2757778/nhs sustainability model _february_2010_1_.pdf

43 Networks NHS. https://www.networks.nhs.uk/

44 Community Q. The Health Foundation. 2018. https://q.health.org.uk/

45 Health Education England. e-learning for healthcare. https://www.e-lfh.org.uk/programmes/ research-audit-and-quality-improvement/

46 Scotland Quality Improvement Hub NHS. QI e-learning. http://www.qihub.scot.nhs.uk/ education-and-learning-xx/qi-e-learning.aspx

47 Joint Royal Colleges of Physicians Training Board. Quality Improvement Assessment Tool (QIPAT). 2017. https://www.jrcptb.org.uk/documents/may-2012-quality-improvementassessment-tool-qipat

48 Joint Royal Colleges of Physicians Training Board. Quality improvement assessment tool. May 2017. https://www.jrcptb.org.uk/documents/may-2012-quality-improvementassessment-tool-qipat

49 Joint Royal Colleges of Physicians Training Board. Multi-source feedback. August 2014. https://www.jrcptb.org.uk/documents/multi-source-feedback-august-2014.

Published by the BMJ Publishing Group Limited. For permission to use (where not already granted under a licence) please go to http://group.bmj.com/group/rights-licensing/ permissionsThis is an Open Access article distributed in accordance with the terms of the Creative Commons Attribution (CC BY 4.0) license, which permits others to distribute, remix, adapt and build upon this work, for commercial use, provided the original work is properly cited. See: $\mathrm{http}: / /$ creativecommons.org/licenses/by/4.0/. 